Meta

Journal des traducteurs

Translators' Journal

\title{
A Matter of Principles: Empirical Treatments of Translation Principles - A Case Study
}

\section{Yong Zhong}

Volume 50, numéro 2, avril 2005

Processus et cheminements en traduction et interprétation Processes and Pathways in Translation and Interpretation

URI : https://id.erudit.org/iderudit/010996ar

DOI : https://doi.org/10.7202/010996ar

Aller au sommaire du numéro

Éditeur(s)

Les Presses de l'Université de Montréal

ISSN

0026-0452 (imprimé)

1492-1421 (numérique)

Découvrir la revue

Citer cet article

Zhong, Y. (2005). A Matter of Principles: Empirical Treatments of Translation Principles - A Case Study. Meta, 50(2), 495-510. https://doi.org/10.7202/010996ar
Résumé de l'article

L'auteur commente les données d'une étude prenant en compte les expériences réelles de la vie de 21 étudiants en traduction avec 2 types de principes de traductions. L'un orienté vers le texte source et son auteur et l'autre vers la traduction et le traducteur. La recherche est axée sur les préférences du traducteur, le raisonnement sur ces préférences et la difficulté de manier les principes de traduction via une tâche traductive et ses stratégies. L'auteur pense qu'il s'agit là d'une première recherche du genre puisqu'il examine les principes des praticiens plutôt que les principes eux-mêmes. Le lecteur trouvera ici des discussions concernant les modalités de la recherche, leur méthodologie, une analyse quantitative succincte ainsi que des analyses qualitatives détaillées et une étude de cas. 


\title{
A Matter of Principles: Empirical Treatments of Translation Principles - A Case Study
}

\author{
YONG ZHONG \\ University of New South Wales, Sydney, Australia \\ y.zhong@unsw.edu.au
}

\begin{abstract}
RÉSUMÉ
L'auteur commente les données d'une étude prenant en compte les expériences réelles de la vie de 21 étudiants en traduction avec 2 types de principes de traductions. L'un orienté vers le texte source et son auteur et l'autre vers la traduction et le traducteur. La recherche est axée sur les préférences du traducteur, le raisonnement sur ces préférences et la difficulté de manier les principes de traduction via une tâche traductive et ses stratégies. L'auteur pense qu'il s'agit là d'une première recherche du genre puisqu'il examine les principes des praticiens plutôt que les principes eux-mêmes. Le lecteur trouvera ici des discussions concernant les modalités de la recherche, leur méthodologie, une analyse quantitative succincte ainsi que des analyses qualitatives détaillées et une étude de cas.
\end{abstract}

\section{ABSTRACT}

In this paper, the author will discuss findings of an investigation into the real life experiences of 21 trainee translators with two types of translation principles, one that is biased towards the source text and its author and the other biased towards the translation and the translator. The investigation centred on the translators' preferences of principles, rationalization of their preferences, their difficulty in tackling the principles via a translation task and their strategies for coping with the difficulties. The author believes that this investigation is the first of its kind in translation studies as it examines practitioners of principles rather than the principles themselves and, therefore, it warrants special attention.

Readers will find in this paper summary discussions about research design, research methodology, a brief quantitative analysis, detailed qualititative analyses and a case study.

\section{MOTS-CLÉS/KEY-WORDS}

translation principles, pedagogy, choices, literal translation, translation of meaning, problem-based solutions

\section{Introduction}

This paper discusses findings of a research project designed to study trainee translators' empirical experiences with two types of principles. The principles are borrowed from Savory's collection of principles and are grouped into two types by the researcher for purely heuristic purposes. To undertake the project, the researcher has adopted two premises. Firstly, no principles are natural or final but rather they are invariably biased and have an expiry date. Secondly, the hypodermic pedagogical approach towards principles has been used to corner trainee translators into what the researcher called 'the discursive impasse of accuracy' (Zhong 2002: 576). So the project is not just another endeavour to consecrate a principle or set of principles 
over others. Rather, it is concerned with investigating attitudinal and empirical experiences of selected principles by the users. It aims to explore the following research questions in relation to the subjects' experiences with the principles.

- Why do they choose one type of principles over the other?

- What do they think of and how do they rationalize their selected principles?

- What problems, linguistic, psychological or pedagogical, do they encounter when they apply any of the selected principles in an actual translation task?

- How do they tackle the problems in the process of applying the principles to the translation task?

In designing this research, the researcher had envisaged that it would achieve a number of academic objectives. To name a few, it would enhance awareness of the validity and practicality of different principles, generate knowledge about their uses/abuses and users/abusers, and, of equal importance to translation teachers like the researcher himself, provide pedagogical insights into the teaching of the principles. Furthermore, it would emerge as a belated attempt to transcend the long-standing debates over the inherent nature of translation and merits of principles and to expand to studies about people doing translation.

\section{Project description, subjects, questionnaire, etc.}

\section{Subject descriptions}

Twenty-one students participated in this project. They were all students at undergraduate levels, completing bachelor degree studies in different disciplines ranging quite randomly from humanities subjects to natural sciences and law studies at the University of New South Wales, Sydney. The samples were of rather diverse cultural and linguistic backgrounds, comprising of males and females; local and international students; nationals of Australia, Mainland China, Taiwan, Hong Kong and Singapore; native speakers of Mandarin, Cantonese and English. Among them, three claimed to be aspiring to be professional translators/interpreters or to pursue careers that would incorporate translation/interpreting skills in the professional portfolios. One of the three, who intended to become a bilingual solicitor, will be featured in a case study in this paper.

At the time of this project, as enrolled students in a general Chinese-English translation subject, they had had four hours of instructions in basic translation concepts, such as different schools of translation theories and terminology and had completed a translation from English into Chinese. As the lecturer of the subject, the researcher had painstakingly refrained from showing his own preference for any schools of thoughts or principles over others.

\section{Research procedures and questions}

The project followed the following procedures, including preparation (i.e., constructing two types of principles, designing a questionnaire and selecting a source text), surveying and interviewing subjects, and analysing and interpreting data. 


\section{The principles}

While recognizing that 'there are no universally accepted principles of translation, because the only people qualified to formulate them have never agreed among themselves,' Savory (quoted in Venuti 2002: 393) collated a widely quoted list of contradictory principles. For the purposes of this project, the researcher selected ten of the principles, which he then grouped into two types, one that was biased towards the source text (ST) and the other towards the translation text (TT). Following are the principles in the two categories.

Group A principles, i.e., principles biased towards the ST

1. translation must give the words of the original.

2. translation must give the ideas of the original.

3. translation should reflect the style of the original.

4. translation should read as a contemporary of the original.

5. translation may never add to or omit from the original.

Group B principles, i.e., principles biased towards the TT

a. translation may add to or omit from the original.

b. translation must be coherent in its reproduction of ideas.

c. translation should read like a translation.

d. translation should possess the style of the translator.

e. translation should read as contemporary of the translator.

\section{Questionnaire}

For the project, the researcher designed a questionnaire that contained both closeended and open-ended questions. The close-ended ones were meant to measure the perceived importance of the principles to the subjects and open-ended ones to explore the motivational, attitudinal issues involved in the selection/application of and experiences with the principles. The open-ended questions were again used in indepth discussions with selected subjects, three of whom are to be profiled in the case studies of this paper.

\section{Surveying and interviewing the subjects}

The researcher distributed to each of the twenty-one subjects a source text (ST) in Chinese entitled 高血脂会不会遗传 (Is Hyperlipidaemia Hereditary) and a questionnaire. The subjects were asked to

1. first translate the ST into English to 'the best of their knowledge and competence' and to 'what they think are the best possible effects' by applying a set of principles which they regarded as best for the task,

2. then complete the questionnaire on the basis of their experiences with their selected principles.

The subjects were asked to undertake the translation and complete the questionnaire separately and independently in the space of 24 hours. They were reminded that they could change and revise their answers to the questions or discuss them with the researcher. Three subjects actually turned up for very lengthy discussions and they were then profiled in the case studies. 


\section{Source text for translation}

For this project, the researcher intentionally selected a text, which was not very familiar in content to ordinary readers and contained special jargons. This was in order to create some difficulty so as to necessitate conscious selection of principles and to motivate subjects to think and rethink their selections and to envisage consequences of their selections. The source text and a rendition by one of case study subject are attached to this paper.

Appendix No. 1 is the ST and a rendition by one of the three subjects profiled for the case study (Subject A) is provided in Appendix No. 2.

\section{Data and data analysis/interpretation}

\section{Preference for principles biased towards ST}

Of the twenty-one responses, eighteen selected Group A principles including two who had initially chosen Group B principles and then switched to Group A, three adopted Group B principles. These statistics represented an apparent bias (about $80 \%$ ) in this relatively small sample towards those principles biased towards the ST. Figure 1 is a graphic representation of the subjects choosing Group A and Group B principles respectively.

FIGURE 1

Graphic representation of the subjects choosing Group A and Group B principles respectively

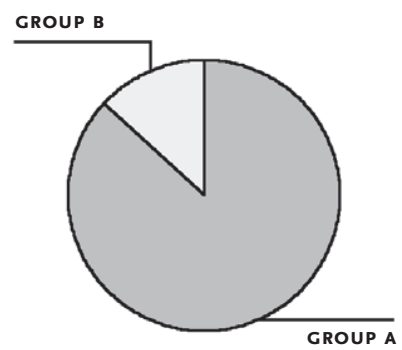

The researcher undertook statistical analyses of the responses, descriptions of which are presented in Figures 2 and 3. While one can derive various computations and permutations on the basis of the statistics, the researcher found the following tendencies, which were of significance and/or constituted some surprise to him.

1. In both groups, the subjects tended to agree with the principles relating to the treatment of 'ideas,' more so than with any other principles.

2. In either group, some principles were less acceptable or relevant than others in the same group to the subjects. This was so that only half of the subjects adopting Group A principles agreed with the 'never adding to or omitting from' principle (mean=2.50) and even fewer adopting Group B principles agree with the 'reading as contemporary of the translator' principle (mean=1.67). 
FIGURE 2

Descriptive statistics regarding Group A principles

Descriptive Statistics

\begin{tabular}{|l|c|c|c|c|c|}
\hline & N & Minimum & Maximum & Mean & Std. Deviation \\
\hline $\begin{array}{l}\text { A translation must give the words } \\
\text { of the original }\end{array}$ & 20 & 2 & 5 & 3.90 & .91 \\
\hline $\begin{array}{l}\text { A translation must give the ideas } \\
\text { of the original }\end{array}$ & 20 & 1 & 5 & 4.55 & 1.10 \\
\hline $\begin{array}{l}\text { A translation should reflect the style } \\
\text { of the original }\end{array}$ & 20 & 3 & 5 & 3.90 & .79 \\
\hline $\begin{array}{l}\text { A translation should read as } \\
\text { a contemporary of the original }\end{array}$ & 20 & 1 & 5 & 3.40 & 1.14 \\
\hline $\begin{array}{l}\text { A translation may never add to or omit } \\
\text { from the original }\end{array}$ & 20 & 1 & 4 & 2.50 & 1.15 \\
\hline Valid N (listwise) & 20 & & & & \\
\hline
\end{tabular}

FIGURE 3

Descriptive statistics regarding Group B principles

Descriptive Statistics

\begin{tabular}{|l|c|c|c|c|c|}
\hline & $\mathrm{N}$ & Minimum & Maximum & Mean & Std. Deviation \\
\hline $\begin{array}{l}\text { A translation may add to or omit from } \\
\text { the original }\end{array}$ & 3 & 3 & 5 & 3.67 & 1.15 \\
\hline $\begin{array}{l}\text { A translation must be coherent } \\
\text { in its reproduction of ideas }\end{array}$ & 3 & 3 & 5 & 4.33 & 1.15 \\
\hline $\begin{array}{l}\text { A translation should read like } \\
\text { a translation }\end{array}$ & 3 & 2 & 5 & 3.67 & 1.53 \\
\hline $\begin{array}{l}\text { A translation should possess the style } \\
\text { of the translator }\end{array}$ & 3 & 2 & 5 & 3.67 & 1.53 \\
\hline $\begin{array}{l}\text { A translation should read as } \\
\text { contemporary of the translator }\end{array}$ & 3 & 1 & 3 & 1.67 & 1.15 \\
\hline Valid N (listwise) & 3 & & & & \\
\hline
\end{tabular}

\section{Rationalization of the preference}

The project investigated why the subjects selected a set of principles over others and, by doing so, also studied how they rationalized their selection. Discussions provided in this paper will concentrate on those subjects who selected Group A principles as the data generated about them is relatively plentiful and warrants detailed interpretations.

In the project, each subject was invited to name two to three reasons that had motivated their selection of either Group A or Group B principles. A total of fortyone reasons for adopting Group A principles and a total of eight reasons for adopting Group B principles were produced in the survey. The researcher then examined the reasons which he heuristically classified into five major areas in relation to the preference for Group A principles. As the project was not meant to be a quantitative 
study, no efforts were made in this paper to delve into the statistics except listing them, starting with areas of most concern to the subjects. The five areas of reasons are:

1. Mission and nature of translation.

2. Credibility and technicality of the ST.

3. Practicality and feasibility of the principles (also in comparison to alternative principles)

4. Roles of the translator, especially in relation to the author

5. Legal consequence of translation.

Though the subjects had been inducted only very recently into the discipline of translation, the conventional ideas regarding nature and mandate of translation seemed to have been already ingrained in their conceptualization. By resorting to the familiar language comprising such discursive jargons as 'faithful,' 'accurate' and 'precise,' the subjects stated their conviction that 'translation is not writing,' that 'translation is about transmitting the ideas of the original author rather than those of the translator' and that 'translation must be faithful to the original in order to be translation.'

Respect for the ST, including its credibility and technicality, featured prominently in the subjects' preference for Group A principles as they reportedly felt that they must preserve the 'professional impression,' 'feel' or 'authoritativeness' of the original text. In the words of a respondent, only Group A principles could 'prevent translation readers from doubting that the original article was written by a medical specialist.' The technicality of the ST, including its medical messages and jargons, also motivated the selection because, as one of them put it, 'the source text contains lots of technical terms, allowing little freedom for the translator to exhibit his/her own style.'

The practicality of the principles had to do with their feasibility and instrumentality in translation. Consideration of practicality featured in the preference of some students, including both those whose lack of English proficiency restrained their work and those confident and competent English writers. Typical of the former kind was a subject to whom Group A principles 'provided a more straightforward approach than the other principles for tackling the task.' Representative of the latter kind was another subject who 'felt academically challenged by the seemingly impracticality of the principles' and 'was motivated to strive to adequately translate every aspect of the author.' There was also doubt about the practicality of Group B principles which were said to be 'not suitable to medical information texts' and 'not definitive enough' for serious translation. In relation to the two subjects who converted to Group A principles, their conversion seemed to have been prompted by the 'impracticality' of Group B principles which they found appealing at first sight but impossible to implement when they actually tried to tackle the translation task.

A perceived self-insufficiency on the part of the respondents as translators in relation to the original authors underlined the preference for Group A principles. A respondent sounded commonsensical when he said '(We) are not medical specialists and have inadequate knowledge. Therefore, anything other than preserving a hundred percent of the original messages and words will fail both the original author and the translator.' Another respondent showed a sense of self-subordination with an assertion that 'translators are meant to be a pen in the hand of someone else who is more important and knowledgeable.'

Last but not least, there was a consideration of the effects of translation in some subjects who adopted Group A principles. ${ }^{1}$ The effects ranged from the purposes of 
translation as dissemination of information across language to the legal consequence of translation. One of the subjects pointed out that 'an unfaithful rendition of a specialized medical text cannot be reliably used by the target readers.' According to another subject, 'an unfaithful translator will lose the confidence of his users and will lose future work opportunities.' A third subject asserted that 'a translation faithful to the original can avoid mistakes and unnecessary (legal) troubles in real-life practice and work.'

\section{Brief Discussion of selectors of Group B principles}

As previously indicated, three of the respondents chose to adopt Group B principles for the task and named a total of eight reasons for their choice. As those adopting Group A principles, they also showed respect for the nature of the source text, consideration for the practicality of the principles, lack of confidence in alternative principles. Furthermore, their preference seemed to be relative to their negative attitude towards alternative principles. For example, among the reasons identified are:

'Group B principles are easier to conform with and Group A ones make the job impossible.'

'Conformity with Group A principles will make the rendition syntactically rough and seemingly unprofessional.'

'The jargons of the source text are too many and too difficult and many of them do not have equivalents in the target language. So a translator must have the freedom to recreate those jargons.'

What differentiated the three students from the rest was, firstly, an obvious absence of 'belief in the mission/nature of translation.' Secondly, they had a stronger consideration for the impact of the rendition and their consideration centred not on the 'quality' of the translation but rather on the target readers of the translation. One of them argued that 'Group B principles allow translators to find or create a more appropriate style, which can be made more contemporary and relevant, in order to produce a more reader-friendly rendition.' Thirdly, there was a sense of empowerment associated with their chosen principles as, I quote one of the three, 'Group A principles restrict a translator's subjectivity and creativity by tethering him to the original.' On the basis of the limited sample, the selection of Group B principles seemed to have to do with an enhanced appreciation of readers and a different perception of the role of the translator and nature of his/her work.

\section{Attitudinal opinions about individual principles}

In addition to examining the rationalization of selected principles, the questionnaire was also designed to investigate the subjects' opinionated reaction to individual principles by inviting them to voluntarily comment on them. Generally speaking, the findings indicated that the subjects thought differently about different principles in the same group and that not all subjects endorsed or were willing to comply with every principle of their selected group. This was not a surprise to the researcher as the subjects were required to adopt the principles by the group rather then selectively from either group. 
Of the five Group A principles, the one on giving 'the ideas of the original' was almost universally accepted by their proponents. Its merits were justified with reference to the medical nature of the ST, the responsibility of the translator (as an invisible bridge of communication), the importance of the inherent messages of ST, the expectation of the readers (to be informed by the author rather than the translator) and 'the predominance of ideas over words.'

In comparison, the principle of 'never adding to or omitting from the original' was most divisive. Over half of the subjects were unwilling to comply with it, pointing especially to its unfeasibility and impracticality. I quote one subject, 'it is impossible not to add or omit. Complying with this principle can actually render a translation unreadable and nonsensical to the target readers.' Another subject argued that this impractical principle 'should be ignored in real life practice' because adding and omitting enabled a translation 'to be understandable without changing the meaning of the original.' Still another subject even endeavoured to subvert the principle into 'a translation must always add to or omit from the original whenever it is necessary.' On the other hand, those supportive of the principle usually stuck to the inherent nature of the ST and responsibility of a translator, insisting that translators/ translation 'must be faithful' or else that the translation would become 'inaccurate' or 'unreliable.'

The principle of 'giving the words of the original' was quite divisive too. On the one hand, there were those subjects who believed that the medical nature and language of the ST as well as the ethical responsibilities of the translator necessitated the principle. On the other hand, there were those other subjects who believed that translation was about tackling meaning rather than words. Clichés were present in both perspectives, including: 'translation of words made real translation' vs 'you can never translate anything word for word.' But there was also what the researcher considered to be an alternative and quite insightful perspective. A subject found the 'principle' useful because the 'medical article uses lots of jargons and professional terms, which constitute part of the medical information intended for the general consumers.'

Likewise, the principle of 'a translation reflecting the style of the original' also divided the opinions of the subjects but, surprisingly to the researcher, the opposing perspectives both had the readers in their considerations. While some subjects liked the principle because it facilitated 'a better understanding of the source text by the readers' or 'an enhancement of the readers' knowledge of the foreign culture,' others disliked it because it was 'not accessible' or 'reader-friendly.' To the surprise of the researcher, there was one subject who insightfully pointed out that people 'read translations for different purposes.' One of the purposes might be, as she suggested, to 'appreciate an exotic text rather than understand messages or words.' There were other subjects who chose to completely ignore the readership. For example, one of them asserted that translation was about 'reproducing the source text, including its style and whether readers can appreciate the translation is an irrelevant matter.'

The principle of a translation 'reading as a contemporary of the original' attracted minimal comments maybe because the ST selected for this project was a contemporary writing, a fact overlooked by very few subjects. A subject found it impossible to imagine any translator absurd enough to render the text into "pre-medieval" English.' Nevertheless there were subjects commenting in support of the principle, arguing 
that it facilitated 'an adequate understanding of the meaning of the original writing' and that it satisfied some readers' desire 'to appreciate the era in which the original was written.'

\section{Empirical difficulty with Group A principles}

The researcher engaged the subjects in what he called a 'focal-recall' summary of difficulties experienced in the process of tackling the principles while completing a translation task. The focal recall comprised recalling and writing down the difficulties during and right after tackling the translation and discussing the difficulties with the researcher in person on the basis of the written summary. With the focal recall, the researcher tried to identify specific difficulties in kinds and degrees and was able to generate the following generalizations in the respect.

1. All the principles caused some difficulty or other for every subject but, generally speaking, the subjects were most concerned with principles with regard to the treatment of ideas and words.

2. There was very little response regarding difficulty caused by applying principles of 'reflecting the style' or 'appearing to be a contemporary' of the original. This might have been a result of the selection of the ST, which was a contemporary writing.

3. The subjects experienced less difficulty while trying to give 'the ideas of the original' and the difficulty usually had to do with the ability to comprehend technical messages of the ST, i.e., understanding 'the technical information' or the 'special meaning of medical texts.'

4. The subjects experienced the most difficulty while trying to give 'the words of the original' and 'not adding to or omitting from the original.' The difficulty lay in the search for exact equivalents between two drastically different languages and medical literatures, i.e., in one subject's words, 'finding matching terminology for such specialized writing.' To several interviewees, this difficulty was related to the ability to comprehend technical messages of the ST as it involved not only finding equivalents but also understanding 'the exact meaning' of certain words and jargons in the source text.

5. The preference for a principle might not have been prompted by its inherent nature but rather by its perceived ease or difficulty. Very little difficulty was reported in relation to giving 'the ideas of the original' on the one hand but giving 'the words of the original' and not 'adding to or omitting from' caused much angst among the subjects.

6. The perceived difficulty might have had debilitating and crippling effects. For example, to quote one subject, 'never adding or omitting anything made it difficult (for her) to translate even one complete sentence.'

7. The perceived difficulty might motivate the subjects to abandon a principle or principles of their choice in order to finish the translation task.

8. The perceived difficulty prompted many subjects to be aware of their own lack of professional and intellectual sophistication and cultivation. A subject reported that 'I have only limited vocabulary and do not even understand many of the words in the original.' Such self-assessment could exhibit a self-belittling and dis-empowering attitude. I quote two subjects:

'Not being a medical professor, I cannot really write something out in a style that the professor uses and prefers.'

'Translators are always at different levels and often at inferior levels. Otherwise they would be the writer and not the translator. Hence they are unable to reflect the style of the source text.' 


\section{Strategies for tackling difficulty caused by Group A principles}

Through focal recall, the researcher also tried to inventory and categorize the strategies adopted by the subjects for tackling the difficulty caused while trying to implement Group A principles. Four categories of strategies were identified: standard, pragmatic, mental and alternative.

The standard strategies refer to those that the researcher, as a translation academic and practitioner, was familiar with, including consulting dictionaries (both hand-held electronic and hard-copy ones) and seeking external help from teachers and peer students. This category of strategies was commonly used in order to better understand the ST, including its technical ideas and jargons, and to find the most suitable TL equivalents to represent the SL ideas and jargons. However, the strategies were reportedly not always effective, perhaps due to the technical nature of the ST.

The pragmatic strategies were those adopted by the subjects, usually when the first category failed to work, which could be characterized as unorthodox, commonsensical and flexible. Typical of such strategies were 'guessing' and 'paraphrasing' the meaning of the ST, 'describing the meaning of the ST rather than translating its words.' These strategies exhibited a consciousness of the impossible perfection, a desire to 'get the job done and not to be constrained by the principles and an actuality of deviating from the chosen principles. For example, a student reported that she 'tried to approximate the original meaning in the translation rather than translating the "word" because the two principles (of giving the ideas and words of the original) were an impossible combination.' Another student recalled that he 'had to play with language not to achieve equivalence but rather optimal similarities,' asserting that 'since we are required to use the principles, we must use them for the sake of the task and to our advantage.'

The third category identified by the researcher had more to do with mind power determination and hence was named as mental strategies. It was evident especially in one of the subjects sampled in the case study in this paper, who strongly insisted on 'conveying the ideas of the author in a way the author intended and maximally reproducing the original words.' On the basis of knowledge about this subject, the researcher felt that her academic competence, tradition and aspiration and translation skills prompted her adoption of the strategies and, in turn, her adoption of the strategies facilitated her completion of the task. There were several other subjects who claimed to need 'more practice' before being able to implement the principles and to translate competently. This could be interpreted both as a desire for 'more practice' after seeing one's own weakness and an excuse, i.e., a strategy for not implementing the principles.

Last but not least, there were those alternative strategies for implementing the principles, which involved use of the Internet. They included searching for standard equivalents from Internet dictionaries, researching essays and abstracts on the Internet to better understand the topic area, accessing special-purpose chat rooms to seek external advice. One of the subjects actually found a short article on the Internet, which was very similar to the ST, both in words and spirit, which was not surprising in the present age of massive information circulation and reproduction. The researcher regarded these strategies as alternative because they were unknown to him but, nevertheless, they might have been typical of the subjects educated in and belonging to an electronic age. 


\section{Post-translation self-assessment}

The researcher engaged the subjects in self-assessment of the implementation of the principles by inviting them to say whether their translation was consistent with Group A principles. On the whole, the assessment was rather negative and pessimistic. While only two subjects claimed to be 'satisfied' or 'reasonably satisfied,' responses from others ranged from straightforward 'no,' 'impossible, 'unsuccessful' to 'mostly not consistent' and 'partly consistent.' The self-assessment also provided the subjects with another chance to criticize the principles (especially the one of 'not adding to or omitting from the original') for being impractical, to blame the ST for being too 'technical' or to denigrate themselves for being 'professionally inferior' or 'intellectually incompetent.'

\section{Case Study}

The researcher had in-depth interviews with three of the subjects, named A, B and C to preserve their anonymity, who are profiled for a case study in this paper. Subject A was a second year high achieving student studying for a double degree in arts and law and she represented the University of NSW in a recent international mooting competition in Geneva. Of Chinese origin but brought up in Australia, she was a highly competent bilingual writer of Chinese and English. Subject B was a second year student of Hong Kong origin majoring in media and communication. She had been a part-time news translator for a Sydney-based Chinese community paper. While a competent writer of Chinese, she wrote fluently but often ungrammatically in English. Subject C was a third year overseas student from Taiwan majoring in Chinese studies and had no work or translation experience. She was very good in Chinese writing but very inadequate in general English proficiency. I have tabled some basic personal information about the three subjects discussed in this case study.

\begin{tabular}{|l|l|l|l|}
\hline & Subject A & Subject B & Subject C \\
\hline Origin & Australia born Chinese & Hong Kong & Taiwan \\
\hline 1st Language & English & Cantonese & Chinese \\
\hline English competence & Native level & Average & Below average \\
\hline Chinese competence & Near native level & Native level & Native level \\
\hline Academic major & Arts \& Law & Media & Chinese \\
\hline Academic standing & High & Average & Average \\
\hline Working experience & Law & Translation & None \\
\hline
\end{tabular}

To facilitate discussions of the three subjects, I reprint the first paragraph from their translations as an indication of their competence in and style of translation.

\section{Subject A's rendition of the first paragraph of the ST}

Medical experts believe that whether hyperlipidaemia is hereditary cannot be conclusively determined. That is because, in causing blood lipids to increase, other than genetic factors, traditional drinking and eating habits, the amount of exercise, work practices, etc. are also very important. 


\section{Subject B's rendition of the first paragraph of the ST}

According to medical experts, it is difficult to say whether high blood grease is hereditary or not. This is because heredity is only one reason why blood grease increases. Other important reasons include eating and drinking habits, amount of exercises and work styles.

\section{Subject C's rendition of the first paragraph of the ST}

Medical experts cannot generalize whether hyper blood lipid is hereditary or not. Because, except hereditary, there are several factors may cause the increase of blood lipids, such as traditional diet, the amount of physical exercise, and working type.

All the three subjects adopted Group A principles to tackle the translation though Subject B had first chosen Group B principles and then switched to Group A. Yet, their choice seemed to have been motivated by different considerations. In relation to Subject A, professionally, she had a strong belief in translation preserving and communicating the true messages of the author and, academically, she 'wanted to be challenged by Group A principles, in comparison to which Group B principles seemed to be 'a soft option' to her. Subject B initially liked Group B principles because they 'seemed to be simpler, more flexible and easier to use.' But then she gave up on them because, after reading the ST more carefully and a trial with the selected principles, she realized that 'their application would be extremely difficult' to the ST and would 'produce very strange renditions.' She then concluded that Group B principles would not be suitable or easy for an informative medical article like the ST. Subject C seemed to have been restricted to Group A principles by her incompetence in English because they were easier to use than Group B principles by facilitating word-forword translation. Quite surprised, the researcher noted a contrast between her and Subject A who made the same choice for drastically different reasons.

To all three subjects, the five principles in Group A differed in relevance to them. They all thought that a translation must first give the ideas, secondly the words and lastly the style of the original and that it was irrelevant or unnecessary for the translation to read as a contemporary of the original. On the basis of the observation, the researcher found that especially Subject $C$ was very much concerned with giving the words rather than the meaning of the original. As to the principle of not adding or omitting from the original, Subject A embraced it because it made the job more challenging, Subject B disliked it for its 'impracticality' and Subject C claimed to like it because it suited her game plan of translating word-for-word.

The three subjects, of different socio-linguistic backgrounds and with different ease tackling the translation by adopting seemingly the same principles, experienced different difficulties. Subject A only encountered difficulties of very academic and even pedantic nature, which seemed to have been largely of her own making, as she tried to give the words of the original. For example, she thought that the English translation (xanthomatosis) was not an adequate rendition of 黄色瘤 (yellow colour tumour) and therefore she tried in vain to represent the jargon with an English technical jargon that also signified colour and tumour. In comparison to Subject A, Subject $\mathrm{B}$ and $\mathrm{C}$ encountered real and substantial obstacles in practising the principles. Both claiming to be non-medical students and non-native English writers, they had difficulty trying to understand the ST, including its medical concepts and jargons, and 
trying to translate the ST into English. Furthermore, Subject B also found conformity with principles to be different from real life work practice. As a newspaper translator, she was accustomed to meeting the deadline rather than being accurate. In her workplace, 'if you don't understand, forget it and write the next. If it is important and you don't understand, ask other people for help.' Subject $\mathrm{C}$ had the added difficulty of low English competence and had to struggle with not only the jargon but also many ordinary words and sentence patterns.

The strategies adopted by the subjects to tackle the principles in action also differed. Subject A applied the principles selectively and hierarchically, not bothering herself with principles less important to her (e.g., preserving the style of the original or appearing as a contemporary of the original) when she could not manage them all. Her strong determination vis-à-vis challenges, passion to be precise and research ability seemed to have facilitated her application of the principles. For example, when the researcher discussed with her the possibility of using neutral generic words (e.g., hyper blood grease) to render technical jargons (e.g., 高血脂 hyperlipidaemia), A simply denied it as a valid professional strategy and insisted that a qualified translator must somehow find genuine equivalent jargons in English. She actually demonstrated to the researcher how she found equivalents for 高血脂 (hyperlipidaemia) and 黄色瘤 (xanthomatosis) on www.Altavista.com.au and www.Bartleby.com in an efficient search.

Subject B, who switched from Group B to Group A principles when she actually started translating the ST, reported that her strategy of coping with the principles was to bend them. Actually, she conceded that she had bent most of them, which she found restrictive to the subjective power of the translator and disrespectful to the needs of the target translation readers. In order to render those difficult jargons in the ST, she sought help from peer students and colleagues rather than looking up dictionaries and the like. The advice she sought tended to concentrate on what words and sentence patterns could make her rendition more reader friendly rather than on how to apply the principles giving the original ideas or words. She also claimed that, in spite of her halfway defection to Group A principles, she preferred Group B principles and she might use them for translation tasks in the future and in her job. She noted that her job as a newspaper translator required that she work without being bothered by thinking about translation principles and so Group A principles did not suit her.

For Subject C whose English proficiency was limited, the selection of Group A principle was one of necessity and comfort as it provided the only practical approach to the translation task. Actually it was her only available solution to the difficult task. She reportedly broke the ST into manageable and meaningful segments and word sequences, looked up dictionaries for the most likely equivalents in English, contemplated on the 'original intention' of the author, and eventually she linked up all the English equivalent words in what she thought was a logical and grammatical sequence.

All the three subjects were quite satisfied with their achievement in the translation task but had different opinions regarding Group A principles, which they had adopted. Subject A believed that, by trying to apply the principles, she had completed the task in a much more rigorous and professional manner than if she had adopted the alternative principles. Subject B thought that her task was a failure in the application of the disempowering principles but was a success in producing a reader 
friendly informative translation. Subject C alleged that the principles provided the only way of translation for her and justified her word-for-word rendition. But she stated that one day she would like to be able to use the alternative principles when her English became proficient.

\section{Conclusion}

A summary of the three subjects comprising the present case study serves very well as a conclusion of the present paper.

The paper discusses findings of the project that studied the experiences of 21 English Chinese translation students with two radically different sets of translation principles. It examined their choices and practice of the principles, their rationalization of choices, prominent difficulties that they encountered in applying the principles, strategies in coping with the difficulties and, last but not least, their reflections on the principles in the whole process.

First of all, the project found a general preference among students of different socio-linguistic backgrounds and competence towards principles that were biased towards the ST over alternative ones biased towards the target text (TT). But the preference was apparently prompted by drastically different considerations, including a belief in the mandate and nature of translation/translator, nature of the ST, practicality of the principles and a concern for legal consequences. Of the three subjects featured in the case study, one was motivated by a belief in the mandate of translation as well as a desire to be academically challenged. Another chose the principles after defecting from alternative ones and her switch was prompted by the suitability of the principles for the given task. The third made her choice of necessity because only it could enable her to complete the translation.

Secondly, the subjects were generally able to make a distinction between principles of the same group. For example, of all the principles biased towards the ST, they prioritized the ones that gave the 'idea' and 'word' of the ST and would not hesitate to discard the ones that reproduced the 'style' of the ST. Subject A of the case study consciously proposed that the set of principles of her choice 'would only be useful if they were followed in a hierarchical order.' Furthermore, as Subject B of the case study did, the principles were often bent in order to get the job done.

Thirdly, the subjects had very different attitudes about the same principles. Some embraced them as a professional standard and, as exemplified by Subject A, even as an academic challenge. Some, as in the case of Subject B, disliked them because of their suppressiveness and disrespect for the translator and reader. Still others, like Subject C, looked upon the principles of her choice as a contingent instrument for getting a job done.

Fourthly, the subjects encountered different difficulties while complying with the principles in the process of a translation task and, seemingly naturally, they resorted to different strategies in coping with the difficulties. Subject A used her strong determination and research capacities, Subject B bent the principles and followed her industry practice and Subject $\mathrm{C}$ used it to justify her word-for-word translation.

Incidentally, I had assumed that, being only recently inducted into the discipline, the subjects would not have very sophisticated knowledge about the principles. The 
findings of the research surprised me enormously to a realization about how deeply ingrained the principles are in the minds of most of the subjects.

- Finally, the project created a new perspective for the researcher, himself a translation teacher, to look at the principles and to contemplate the following questions:

- What shall we do about seemingly commonsensical principles when they make students/practitioners feel suppressed?

- Knowing students are all different from each other in their experiences with and abilities to cope with principles, shall we impose the same principles or shall we encourage different individuals to practise different principles?

- Where there is a seemingly natural inclination for principles biased towards the ST, shall we inspire and encourage students to explore and experiment with alternative principles biased towards the TT?

- Knowing that principles can be bent in actual practice, shall we teachers encourage students to explore different strategies for coping with the principles or shall we simply enjoin the students to comply with them blindly?

\section{APPENDIX NO. 1}

Chinese ST for the translation task ${ }^{2}$ : (The subjects were required to translate the text into English by implementing their selected principles.)

\section{高血脂会不会遗传}

李全忠等 文

医学专家认为, 高血脂究竟会不会遗传, 不能一概而论。因为, 引起血脂升高, 除遗 传因素外, 传统的饮食习惯、运动量的多少、工作方式等因素也是非常重要的。

许多高脂血症具有家族聚集性, 有明显的遗传倾向。这些高脂血症统称为家族性高脂 血症。有些家族性高脂血症的遗传基因缺陷已基本清楚，如家族性高胆固醇血症，它是一 种常染色体显性遗传性疾病, 这类病人常有皮肤多部位的黄色瘤, 并过早地发生冠心病。 一般而言, 有血脂代谢异常家族史者后代出现血脂异常的机会较多。临床上, 常见的一种 所谓 “多基因的” 高胆固醇血症, 虽然有家族聚集性, 但目前尚不能检测出具体的异常基 因。（《家庭医生报》2003.3.10）

\section{APPENDIX NO. 2}

\section{Translation by Subject A featured in Case Study}

\section{Is hyperlipidaemia hereditary? \\ LI Quan-zhong et. al. text}

Medical experts believe that whether hyperlipidaemia is hereditary cannot be conclusively determined. That is because, in causing blood lipids to increase, other than genetic factors, traditional drinking and eating habits, the amount of exercise, work practices, etc. are also very important.

Many hyperlipidaemia types are familial, having a clear hereditary tendency. These hyperlipidaemia types are collectively called familial hyperlipidaemia. The hereditary genetic defect in some types of familial hyperlipidaemia are basically clear, such as in familial hypercholesterolemia, which is a common autosomal dominant disease where patients often have xanthomatosis ${ }^{3}$, and prematurely develop coronary heart disease. Generally speaking, descendants of those with a family history of abnormal blood lipid metabolism have more chances of developing blood lipid abnormality. In clinical studies to date, it has not been possible to detect the specific defective gene in a common type of, so-called "multiple genetic," hypercholesterolemia, even though the condition is familial. 


\section{NOTES}

1. Purposefully looked for signs of awareness of translation impact from the subjects as I was particularly sensitive to impact of translation, both perceived and empirical impact, and I am now authoring and co-authoring a number of articles in the area and will seek to get them published.

2. The ST was sourced from a Chinese Language Paper entitled Family Doctor Paper, dated 10 March, 2003.

3. The translator inserted a footnote for the term which I reprint here: 'The literal translation of the Chinese term for "xanthomatosis" is "dermatological multi-positional yellow tumour," which perhaps better describes the condition.'

\section{REFERENCES}

Gutt, E.-A., (2000): 'Translation as Interlingual Interpretive Use', in Venuti, Lawrence (ed.) The Translation Studies Reader, London and New York, Routledge.

Zhong, Y., (2003): 'Transcending the Discourse of Accuracy in the Teaching of Translation,' META, 47-4, p. 575-585. 